\title{
EVALUATION OF THE FATIGUE RESPONSE OF POLYESTER YARNS AFTER THE APPLICATION OF ABRUPT TENSION LOADS
}

\author{
Emilio Luiz Vieira Louzada ${ }^{a, *}$, Carlos Eduardo Marcos Guilherme $^{a, b}$, \\ FELIPe Tempel STUmpF ${ }^{a, b}$
}

a Programa de Pos Graduacao em Engenharia Mecanica, Av. Italia, km. 8, Rio Grande, Brazil

b POLICAB, Av. Italia, km. 8, Rio Grande, Brazil

* corresponding author: emilioluizlouzada@gmail.com

\begin{abstract}
The discovery of oil fields in deeper waters through out the last decades has led the oil industry to the necessity of replacing the mooring systems of offshore platforms from steel to synthetic cables. Consequently, both the industry and the academy started to join forces in order to better understand the mechanical behavior of such materials when subjected to different service conditions. This work aims to assess the change in the fatigue life of polyester (PET) yarns if the material is submitted to an abrupt tension load prior to the application of the fatigue cycling. It was found that the fatigue life of the yarns tested are substantially reduced if the specimen is subjected to this kind of abrupt load in comparison to virgin samples.
\end{abstract}

KEYWORDS: mooring lines, synthetic cables, offshore platforms.

\section{INTRODUCTION}

In the course of the last decades, offshore oil fields had been discovered along the brazilian shore in increasingly deeper waters throughout the years, which forced the oil industry to look for mooring systems to substitute the traditional systems based on steel cables. With the increase of the water depth in which the platform will operate, these systems tend to become potentially heavy, to the point where the mooring system weight itself could overcome the platform floating forces, leading to the sinking of the structure [1, 2].

In order to overcome this situation, the oil industry started to look for lighter mooring systems, which meant lighter materials, and the obvious choice was to invest in the development of mooring cables based on polymeric materials. However, there was a lack of understanding regarding these materials' mechanical response when submitted to the service conditions of an offshore platform, which basically forced the engineers and academics to develop new research in the field [1-3].

In the present days, polyester (PET) is found to be a widely used material in applications such as anchoring cables. Its good performance when submitted to cyclic loadings and the fact that its fatigue life is not affected by its submersion in salt water was the main reason it was the first material to be considered by the industry to such application [4. However, if the maximum tension force is considerably high, the fatigue life of PET is dramastically reduced [5]. It was found that when operating between cyclic tension loads of $10 \%$ and $70 \%$ of the material's tension resistance, samples failed after approximately 100,000 cycles [6]. If the maximum load is reduced to $60 \%$ of the material's yarn break load (YBL), fatigue life increases to 1,000,000 cycles [5].

Cyclic tension loads, however the main loads to which the cables are submitted during service, are not the only ones. During the installation of the anchoring cables, the launch of the torpedo anchor might eventually be submitted to a sudden stop, caused either by a failure of the launching system or even due to a stop because of heavy weather conditions, which would lead to abrupt axial tension loads in the synthetic cable being launched/installed. It is expected that this kind of sudden (high) tensile load affects the future mechanical behavior of the polymeric material, specially its fatigue life.

This paper aims to correlate the change in the behavior of PET under cyclic loadings before and after it was submitted to abrupt axial loads. Such study will be based on the material's diagram relating number of cycles up to failure $(\log N)$ and the minimum tension load throughout the cyclic loading.

\section{Materials and Methods}

The material used was polyester (PET). Yarn samples were of $500 \mathrm{~mm}$ length with sandwich-type terminals (Figure 1] [7. Prior to the application of the impact load, and throughout all the tests, the samples were left 24 hours at controlled temperature of $20 \pm 2^{\circ} \mathrm{C}$ and relative humidity of $65 \pm 4 \%$.

Tension tests were carried out in an EMIC DL-2000 electromechanic universal testing machine in order to obtain the material's YBL of virgin samples. Using a $500 \mathrm{~mm} / \mathrm{min}$ displacement ramp, and ten specimen, it was found that this PET has an YBL of 165,44 N. 


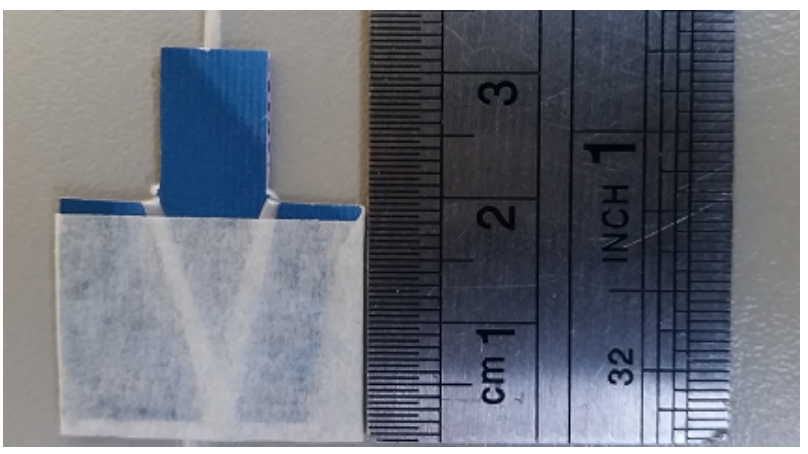

Figure 1. Sandwich-type terminals.

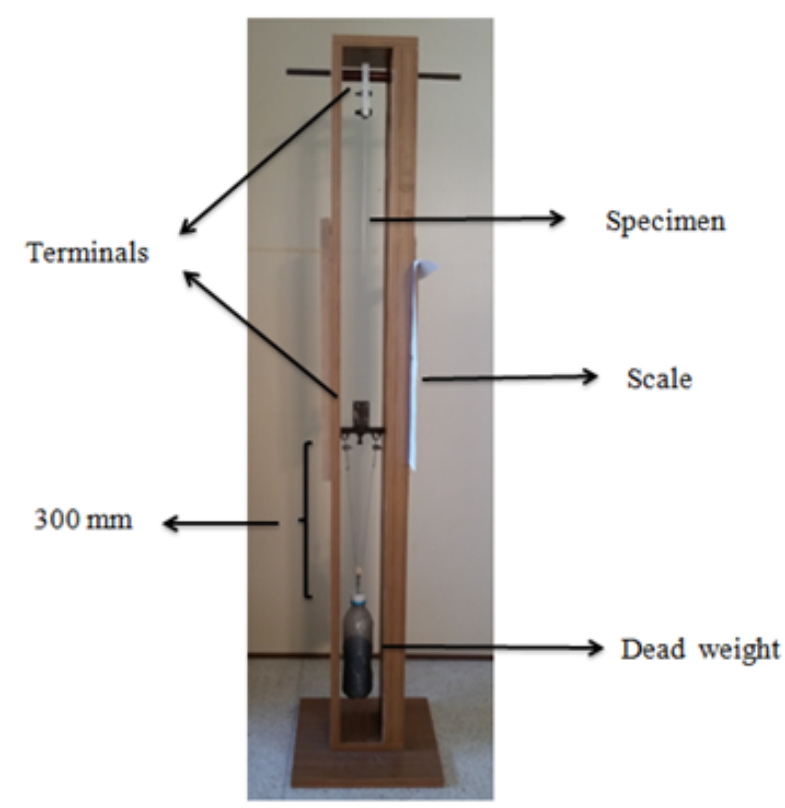

Figure 2. Impact testing device.

A set of virgin samples were taken to the impact testing device (Figure 2) and submitted to an axial impact load corresponding to $10 \%$ of the material's YBL. This load is achieved releasing a $1.7 \mathrm{~kg}$ dead weight from a $300 \mathrm{~mm}$ height, which transfers to the sample a potential energy of $5 \mathrm{~J}$. The maximum elongation of the samples were measured using a marker attached to the bottom end of the yarns running along a ruler.

After the impact test, each specimen is taken to an INSTRON 8801 servohydraulic unversal testing machine to be submitted to force-controlled cyclic tension loads. A total of eight ranges of tension loads were used during the cyclic tests: 10-90\% YBL, 2090\% YBL, 30-90\% YBL, 40-90\% YBL, 50-90\% YBL, 60$90 \%$ YBL, $70-90 \%$ YBL, $80-90 \%$ YBL. The frequency used was $0.1 \mathrm{~Hz}$.

The same fatigue procedure was applied to virgin samples, in order to compare their behavior with those damaged by the impact. Each load range was applied to ten different samples (both virgin and damaged by the impact test), which means that a total of 160 yarn samples were used throughout the fatigue assessment.

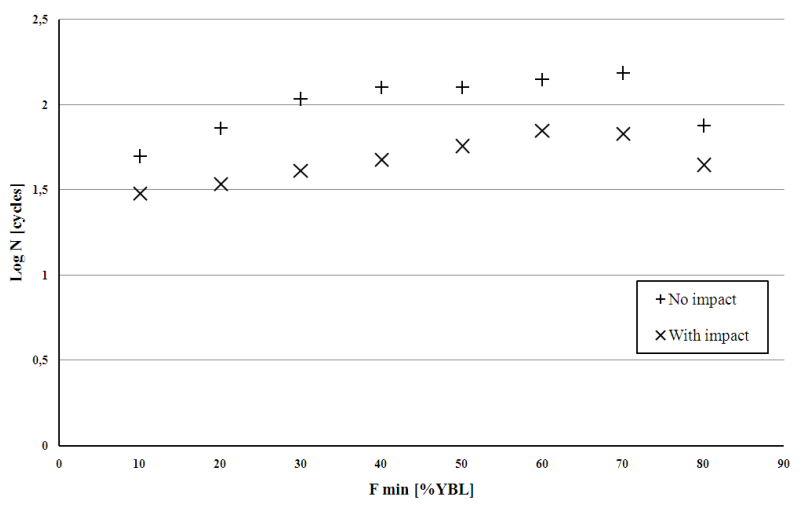

Figure 3. Cycles up to failure versus load ranges: superposed results.

\section{Results}

\subsection{EFFECT OF IMPACT LOAD ON THE FATIGUE LIFE OF PET}

Figure 3 shows the number of cycles up to failure versus the minimum load of each load range in the case of virgin samples and damaged samples. Regardless of the minimum load applied, the virgin samples have a longer fatigue life compared to the ones that were previously submitted to the abrupt tension load. Table 1 sumarises the number of cycles up to failure for both cases for each load range.

\subsection{EFFECT OF IMPACT LOAD ON THE YARN ELONGATION}

Together with the tests to determine the material's YBL, data regarding the samples elongation in rupture were collected. That was made in order to compare the elongation in rupture of the samples submitted to the quasi-static tests performed on the universal testing machine with those obtained when the yarns fail due to impact only. It was found that a potential energy of $6.5 \mathrm{~J}$, which corresponds to a tension load of $13 \%$ of the material's YBL, is required to take the yarns to fail by impact only. A set of ten samples were submitted to this condition and a scale was used to get the yarn's elongation in rupture. Results comparing the elongation of the yarns during quasi-static test and dynamic test are shown in Table 2 It was found that the samples tend to elongate considerably less in rupture when the load applied is abrupt $(51.6 \mathrm{~mm}$ versus $57.5 \mathrm{~mm}$ of the quasi-static tests).

\section{Conclusions}

The present paper showed a preliminary assessment of the change in the fatigue life of polyester yarns when they are submitted to an abrupt axial load in comparison to the virgin material, and it was found that a sudden load of approximately $10 \%$ of the yarn break load is enought to lead the material to a considerable drop on its fatigue resistance. In terms of the yarn's elongation in rupture, it was also found that quasi-static tests lead to a larger elongation, and it 


\begin{tabular}{lllllllll}
\hline Minimum load [\% YBL] & $\mathbf{1 0}$ & $\mathbf{2 0}$ & $\mathbf{3 0}$ & $\mathbf{4 0}$ & $\mathbf{5 0}$ & $\mathbf{6 0}$ & $\mathbf{7 0}$ & $\mathbf{8 0}$ \\
\hline Virgin samples & 50 & 73 & 108 & 127 & 127 & 141 & 153 & 75 \\
\hline After impact & 30 & 34 & 41 & 48 & 57 & 71 & 68 & 44 \\
\hline
\end{tabular}

TABLE 1. Number of cycles up to fatigue rupture.

\begin{tabular}{ll}
\hline \multicolumn{2}{l}{ Elongation in rupture } \\
\hline Quasi-static test & $57.52 \mathrm{~mm}$ \\
\hline Impact test & $51.6 \mathrm{~mm}$ \\
\hline
\end{tabular}

TABLE 2. Elongation in rupture for quasi-static and dynamic tests.

can be explained basically by the viscoelastic behavior of the material, because during the impact load the material has no time to dissipate the potential energy in terms of heat energy, for example. It is also interesting to notice that a sudden load of only $13 \%$ of the material's yarn break load is sufficient to lead to its rupture by impact, which is considerably low and could be used to warn the industry to take that into consideration when operating with mooring ropes made of polyester.

\section{REFERENCES}

[1] C. J. M. del Vecchio. Light weight materials for deep water moorings. PhD Thesis 1992.

[2] M. M. Salama. Lightweight materials for mooring lines of deepwater tension leg platforms. Marine Technology 21(3):234-241, 1984.

[3] F. E. G. Chimisso. The past, the present and the future of policab: The challenge of synthetic mooring ropes anchorages at pre-salt petroleum basin, in brazil.
Proceedings of the 10th Youth Symposium on Experimental Solid Mechanics 2011.

[4] R. R. Rossi. Cabos de poliester para ancoragem de plataformas de petroleo em aguas ultraprofundas, in portuguese. MSc Thesis 2002.

[5] F. V. de Carmago, C. E. M. Guilherme, C. Fragassa, A. Pavlovic. Cyclic stress analysis of polyester, aramid, polyethilene and liquid crystal polymer yarns. Acta Polytechnica 56(5):402-408, 2016. DOI:10.14311/AP.2016.56.0402.

[6] R. L. Bosman. On the origin of heat build-up in polyester ropes. OCEANS96 MTS/IEEE Prospects for the 21st Century Conference Proceedings 1996.

[7] D. Pfarrius, E. Duarte, F. E. G. Chimisso. Theoretical and experimental modeling of a socket sandwich for use in tension tests of synthetic ropes. Proceedings of the VIth Youth Symposium on Experimental Solid Mechanics 2007. 